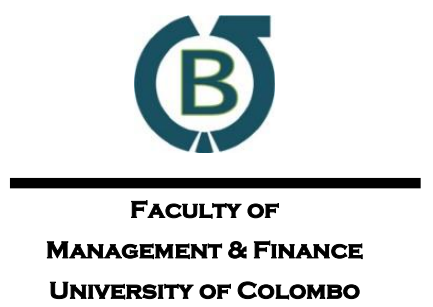

\title{
Chain of Reflective Experiences: How Tourists Give Meaning to Intangible Cultural Heritage Experiences
}

\author{
Thilini Alahakoon $\bowtie$ \\ Postgraduate Institute of Management, University of Sri Jayawardenepura, Sri Lanka
}

\begin{abstract}
Intangible Cultural Heritage (ICH) is a tourist offer that is embedded within the people of a destination and their lifestyles. Given this nature of $\mathrm{ICH}$, this paper aims to explore how tourists give meaning to ICH experiences especially in the absence of formal sources of information. It employs a qualitative phenomenological stance with a sample of 21 European tourists. The Appropriation Theory was used for theoretical support. Findings indicate that recollections and reflections of past travel experiences contribute to the interpretation of ICH experiences. Specifically, such recollections and reflections create a sense of familiarity with new ICH experiences allowing tourists to connect with them more, resulting in subjective meaning assignment which may or may not be the meaning envisioned by destination marketers and the host community. This study also initiates a discussion on 'chain of reflective experiences', through which further exploration of the effects of past travel experiences on new experiences are encouraged.
\end{abstract}

Keywords: Intangible Cultural Heritage, Past Travel Experiences, Appropriation Theory, Heritage Tourism, Tourist Experience

Received:

15 August 2020
Accepted revised version: 28 January 2021
Published:

30 June 2021

Suggested citation: Alahakoon, T. (2021). Chain of reflective experiences: How tourists give meaning to intangible cultural heritage experiences. Colombo Business Journal, 12(1), 29-53.

DOI: http://doi.org/10.4038/cbj.v12i1.70

(C) 2021 The Authors. This work is licensed under a Creative Commons Attribution 4.0 International License which permits unrestricted use, distribution, and reproduction in any medium, provided the original work is properly cited.

$\triangle$ thiliniha@mkt.cmb.ac.lk@ iDttps://orcid.org/0000-0001-7060-6276 


\section{Introduction}

Postmodern tourists use the power of their intellect and imagination to receive and communicate messages, constructing their own sense of historic places to create their individual journeys of self-discovery (Nuryanti, 1996). In such situations, familiarity with a context and/or theme of an event or situation helps consumers dive straight into the relevant experience and immediately become immersed in it (Caru $\&$ Cova, 2006). This notion indicates that tourists' memories and imagination play a vital role in their understanding of and engagement in new experiences. However, research focusing on such memory dimensions and their impacts on travel experiences are limited, resulting in calls for comprehensive explorations of aspects such as recollections (Manthiou et al., 2014), past experiences (Loureiro, 2014) and more specifically, how past experiences affect individuals' evaluation of new experiences (Hwang \& Seo, 2016).

Complementing the aforementioned concerns in experience literature, heritage literature highlights that meaning generation (Freeman, 2010) and memory creation (Kim, 2010) associated with heritage assets including Intangible Cultural Heritage (ICH) need further academic focus. ICH refers to "practices, representations, expressions, knowledge, skills, instruments, objects, artefacts and cultural spaces associated with communities, groups and individuals" (United Nations Educational, Scientific and Cultural Organization [UNESCO], 2003, p. 3) which are embedded within people and their lifestyles. More specifically, ICH includes handicrafts and visual arts, gastronomy and culinary practices, social practices, rituals and festive events, music and the performing arts, oral traditions and expressions and knowledge and practices concerning nature and the universe (World Tourism Organization, 2012). Making it a valuable tourism resource, $\mathrm{ICH}$ is now recognised as a vital economic tool that allows income generation when included in tourism (Lenzerini, 2011). Despite this importance, studies focusing on $\mathrm{ICH}$ as a travel experience is still in its infancy.

Combining the concerns highlighted above, this paper explores how tourists give meaning to ICH experiences. Therein, it uses a psychological perspective to explore the process tourists go through when interpreting new travel experiences through the recollection and reflection of past travel experiences taking $\mathrm{ICH}$ as the specific travel context. In particular, this paper uses the Appropriation Theory to explain this phenomenon leading to the idea of 'the chain of reflective experiences' which suggests that discrete travel experiences have synergistic effects on each other. Within this scope, the significance of the study is two-fold. Firstly, it contributes to 
experience literature by introducing a holistic approach of comprehending the connection between discrete travel experiences separated geographically and temporally. Secondly, it contributes to heritage literature by providing a more indepth understanding of tourists' interpretation of ICH.

The rest of the paper is structured as follows: the proceeding section discusses existing literature related to $\mathrm{ICH}$, past travel experiences and the relevant theoretical lens. The next section details the methodology adopted in the study. This is followed by the analysis and discussion leading on to the conclusion, limitations, and suggestions for further research.

\section{Literature Review}

\section{Heritage Tourism and Intangible Cultural Heritage (ICH) Experiences}

Heritage tourism is one of the most notable and widespread types of tourism (Timothy \& Boyd, 2006) for which the main motivation for visiting would be a destination's heritage characteristics (Poria et al., 2003). In spite of its sustained popularity, cultural heritage traditionally included only tangible elements such as monuments, groups of buildings and sites (UNESCO, 1972) with intangible elements such as handicrafts, visual arts, gastronomy, social practices, rituals, festivals, music, performing arts, oral traditions, expressions and know-how being acknowledged only in year 2003 (Ahmad, 2006). Since then, ICH has received much academic attention evolving to be an emerging tourist attraction (Björk \& Kauppinen-Räisänen, 2016; Cetin \& Bilgihan, 2016; Lopez-Guzman \& Gonzalez Santa-Cruz, 2016).

Despite this growing interest, the ways in which tourists experience ICH remains to be an under researched phenomenon (Lopez-Guzman \& Gonzalez Santa-Cruz, 2016). One reason for this is the gravitation of ICH literature towards the industry/destination perspective, where areas such as power conflicts in ICH management (Beardslee, 2016; Swensen et al., 2013), and preservation of ICH (Mitsche et al., 2013; Yelmi, 2016) have received extensive attention. A second reason is that $\mathrm{ICH}$ resides within the processes, phrases, know-how, and abilities of communities (Petronela, 2016) making it difficult to separate it from the people of a destination and their lifestyles. Regardless of these apprehensions, few research studies explore $\mathrm{ICH}$ as a tourist experience focusing on areas such as $\mathrm{ICH}$ and authenticity of experiences (Nguyen \& Cheung, 2016; Wesener, 2017); visitor perceptions (Lopez-Guzman \& Gonzalez Santa-Cruz, 2016); and meaning-making of ICH in online platforms (Freeman, 2010). Thus, owing to such limited research on 
ICH experiences from the tourists' point of view, this study draws from general heritage literature as well.

Tourism is inherently a marketplace of experiences (Volo, 2009) and heritage tourism is an experiential consumption (Chen \& Chen, 2010). However, as highlighted before, within heritage literature, only a few studies focus on tourists' experience of cultural heritage with even lesser focus on ICH. These studies show that experiences associated with cultural heritage create experiential benefits such as knowledge and narrative connect (Chronis, 2005), generate educational, entertaining, escapist and esthetic experiences (Alahakoon \& Udunuwara, 2018) and are nostalgic to tourists (Ali, 2015). Further, cultural encounters are known to positively affect the autobiographical memory of recollection and vividness of past experiences of tourists (Kim, 2010). Overall, these studies indicate that cultural heritage experiences provide valuable learning opportunities to tourists. Such learning opportunities appear to have long-term applications because when consuming cultural heritage experiences, tourists use their past knowledge and imagination to interpret those encounters (Chronis, 2005). This idea is further expanded by Freeman (2010) who reports that tourists use images shared in online platforms to make meaning of such experiences as a collective. Thus, studies suggest that tourists' memories that include recollection and reflection of past travel experiences serve as useful input when experiencing cultural heritage including ICH. This idea also ties back to experience literature which recognises that storing, reflecting and enriching an experience are important contributions for analysis of other experiences (Aho, 2001) as the tourist experience is often narrated by the tourists themselves (Bendix, 2002). Thus, inferring from these notions it is established that past travel encounters influence how tourists experience new travel experiences specially in the context of cultural heritage.

\section{Past Travel Experiences}

A tourist experience is "a past personal travel-related event strong enough to have entered his/her long-term memory" (Larsen, 2007, p. 15). Larsen (2007) further explains that episodic memory, which refers to an individual's store of factual memories concerning personal experiences, is the most relevant to travel. Such travel related memories are recognised to be unique and subjective (Ritchie \& Hudson, 2009). As such, tourists' memories of past travel experiences are a useful information source (Braun-La Tour et al., 2006) and recollection of such experiences can even prompt actions such as repetition of travel experiences (Li, 2000). Further, from a marketing perspective, past experiences are an important determinant of customer satisfaction of new experiences (Hwang \& Seo, 2016). Drawing from these 
explanations, for the purpose of this study, past travel experiences are identified as tourists' memories of travel experiences that serve as information for new experiences.

The limited yet growing literature on past travel experiences largely focuses on factors affecting the memorability of past travel experiences and constituents of memorable experiences (Park \& Santos, 2017; Tung \& Ritchie, 2011) or impacts of past travel experiences (Kim et al., 2010; Loureiro, 2014). However, Kim (2010) highlights that even though studies on memorability of travel experiences are 'worthwhile and commendable', a clear gap exists in terms of whether tourists really recall and reflect on those memories after the actual event, triggering the need to study this phenomenon expansively.

Interestingly, the consumption of heritage assets generally requires the use of tourists' past knowledge, imagination and creativity (Chronis, 2005) indicating a need to immerse in the experience and actively participate in it. This means that tourists often engage in the experience mentally and physically (Pine \& Gilmore, 1999) playing the role of both the consumer and producer (Toffler, 1980). Particularly, when consuming ICH experiences, tourists employ immersive and active techniques such as socialising with locals, and mirroring locals (Alahakoon \& Udunuwara, 2018). Such immersion and active participation are necessary for $\mathrm{ICH}$ because tourists generally encounter it in the everyday lives of locals with no or little exposure to formal sources of information at the time of consumption.

\section{Immersion in Consumption Experiences}

Immersion is a concept that surfaces as topical in discussions on postmodern consumption because contemporary consumers seek varied experiences that they can immerse in (Firat, 2001). Caru and Cova (2006, p. 5) define immersion as "becoming one with the experience" identifying it as "a total elimination of the distance between consumers and the situation". Complementing this definition, Hansen and Mossberg (2017, p. 2) describes immersion as "total and deep involvement in the present" which in turn determines whether an experience is extraordinary. Extant studies on immersion related to tourism focus on areas such as consuming experiences through immersion (Caru \& Cova, 2006; St. James et al., 2018), and factors that facilitate immersion (Hansen \& Mossberg, 2017; Lunardo \& Ponsignon, 2020). All these studies portray immersion as a popular practice that consumers use to connect with experiences and give meaning to them. Further, within tourism, immersion is identified as a factor that enhances the memorability of tourist experiences 
(Chandralal \& Valenzuela, 2015; Tung \& Ritchie, 2011). Yet, its effects on visitor evaluations of experiences remain to be unexplored within tourism (Lunardo \& Ponsignon, 2020).

For immersion to take place, a consumer should become a participant in customisation of his/her world by engaging him/herself as an object into the world of objects (Firat et al., 1995). Such engagement could be mental or physical; either way, a total immersion in the experience is needed to connect with the environment (Caru \& Cova, 2003). This idea of mental immersion is recognised as absorption by Pine and Gilmore (1999) when referring to the Experience Economy. Further, as a consumption experience, immersion takes a more progressive nature and is often "a moment of intensity that a consumer lives through" (Caru \& Cova, 2006, p.10). Given that past travel experiences are tourists' memories of travel experiences that serve as information for new experiences, the recollection and reflection of such experiences during travel can be considered a mental immersion.

In terms of theories that explain such immersive experiences, the theoretical lens of the Appropriation Theory surfaces as popular (Caru \& Cova, 2006; St. James et al., 2018). This theory posits that consumers use a sequential process to immerse in an experience and give meaning to it. As the recollection and reflection of past travel experiences to interpret new experiences is a form of mental immersion, this study also considers the Appropriation Theory as a suitable lens to explain the process tourists go through when interpreting new travel experiences.

\section{Appropriation Theory}

The Appropriation Theory is a comprehensive theoretical lens that explains the process of immersion. In the sphere of marketing, appropriation is a concept that has been applied to study services (Misfud et al., 2015) and experiences (Caru \& Cova, 2006; St. James et al., 2018). Literature endorse the idea that the goal of appropriation is to connect to an experience by making it one's own by reducing or eliminating the physical, mental, or emotional distance between the consumer and the product in concern (Caru \& Cova, 2003, 2006). The process of appropriation involves three operations: nesting, investigating, and stamping (Aubert-Gamet, 1997; Fischer, as cited in Caru \& Cova, 2006).

The first stage, nesting is where an individual "feels at home because part of the experience being faced has been isolated, a part that is already familiar because of one's accumulated experience and existing foothold in it" (Caru \& Cova, 2006, p. 6). 
This means that when experiencing something new, consumers will try to isolate a familiar element creating a comfortable 'nest' from which they can then explore the rest of the experience (St James et al., 2018). During this stage, consumers feel comfortable with the new experience based on the mental and physical sensations and points of anchorage they recognise (Caru \& Cova, 2006). Accordingly, nesting is associated with familiarity, comfort, group membership and control (Hansen \& Mossberg, 2017).

The second stage, investigating, is where "starting from the nest that has been built up in this fashion, the individual explores and identifies new products or activities so as to develop points of anchorage and control (i.e., signposts)" enhancing knowledge of the context of the experience and progressively extending one's territory (Caru \& Cova, 2006, p. 6). This means that investigating is a progressive exploration of elements of an experience that are not so familiar to the consumer going beyond familiar elements (Hansen \& Mossberg, 2017; St James et al., 2018). To do this, consumers often engage in various investigating operations such as mirroring actions (St James et al., 2018) and observations (Caru \& Cova, 2006).

The third and final stage, stamping, is where "individuals use creativity to play around with the experience's context subjectively and to imbue it with their own personal meaning" (Caru \& Cova, 2006, p. 6). That is, it is in this stage that consumers will engage in meaning making (Hansen \& Mossberg, 2017). Thus, during stamping consumers attach a subjective and unique meaning to the experience informed by their own 'personal story' (St James et al., 2018). Through this, the consumer will interpret the final experience or a part of it making their own meaning attachments which could even be different to the commonly accepted meaning. Thus, as illustrated in Figure 1 below, the Appropriation Theory identifies that individuals' meaning assignment to new experiences are attributable to the process of immersion, where they first find a comfort zone through familiar elements, then progressively go beyond that comfort zone to finally use their own memories and creativity to interpret those experiences.

Figure 1: Visual Representation of the Appropriation Theory

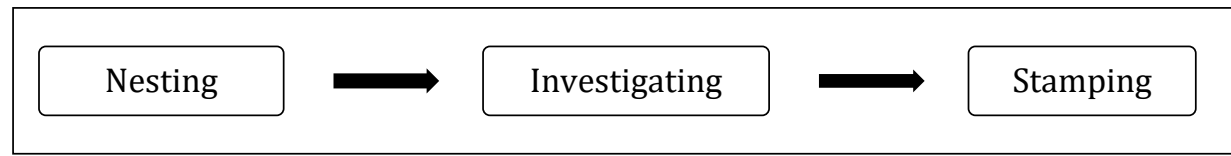

Source: Based on explanations by Caru and Cova (2006) 


\section{Methodology}

This paper set out to explore how tourists construct meaning of ICH experiences. Given the newness of the research focus, a qualitative methodological approach was employed. Accordingly, narrations of tourists who visited Sri Lanka, which were collected through one-to-one semi-structured interviews were used.

Sri Lanka is an ideal destination focus for this study because cultural tourism is acknowledged to be a growth area for Sri Lanka tourism (Liyanag \& Jayawardena, 2013). Further, many researchers hold the view that Sri Lanka has a rich cultural heritage that is part of a tourist's journey (Alahakoon \& Udunuwara, 2018; Blundell, 2013; O'Hare \& Barrett, 1993; Wimalaratana, 2016). This cultural heritage includes components of ICH because it is constructed around religious practices, meditation, yoga, folk music and dances, festivities, ceremonies and rituals apart from historical monuments and ancient cities (Wimalaratana, 2016). Even then, studies on ICH in Sri Lanka are community-specific (Blundell, 2013; Wijetunga \& Sung; 2015), where other areas are not explored, particularly in a holistic way taking Sri Lanka as a tourist destination, providing a significant contextual opportunity for this study. It is also noteworthy that only four categories of ICH consisting of 1) gastronomy and culinary practices, 2) social practices, rituals, and festive events, 3) music and the performing arts, and 4) practices concerning nature and the universe (simplified as livelihoods of locals) are considered in this study as these are the categories that are mostly experienced by tourists in Sri Lanka (Alahakoon \& Udunuwara, 2018).

Further, as the study required the researcher to explore the phenomenon of investigation as felt by the tourists themselves, a phenomenological stance was taken. This means that this study explored "knowledge as it appears to consciousness, or to the immediate awareness and experience" focusing on "the living immediacy of experience as the individual lives it" (Chronis, 2005, p. 215).

As such, a purposive homogeneous sampling technique was employed to recruit participants based on their ability to provide rich information (Patton, as cited in Braun \& Clarke, 2013). Accordingly, individuals 1) who are European, 2) who visited Sri Lanka during the year 2017,3) for the purpose of pleasure/holiday were recruited with the help of snowballing which commenced with the researcher's own contacts. As a result, 21 European tourists who visited Sri Lanka during the months of July to December 2017 were interviewed by the researcher herself. The sample characteristics are presented in Table 1. Thirteen of the interviews were conducted face-to-face in tourist accommodations in Sri Lanka, while 8 interviews were 
conducted through Skype as those tourists had already returned to their home countries. Data saturation occurred at the $19^{\text {th }}$ interview.

Table 1: Sample Characteristics

\begin{tabular}{llllll}
\hline Name* & Gender & $\begin{array}{c}\text { Age (in } \\
\text { years) }\end{array}$ & \multicolumn{1}{c}{ Purpose of travel } & Travel with & $\begin{array}{l}\text { Visitor } \\
\text { status }\end{array}$ \\
\hline Sacha & Male & $18-30$ & Pleasure/holiday & Alone & First time \\
Lorenzo & Male & $41-50$ & Business/pleasure/holiday & Alone & Repeat \\
Nayden & Male & $18-30$ & Pleasure/holiday & With partner & First time \\
Maja & Female & Over 61 & Pleasure/holiday & With partner & Repeat \\
Valter & Male & Over 61 & Pleasure/holiday & With partner & Repeat \\
Ben & Male & Over 61 & Pleasure/holiday & Alone & Repeat \\
Elena & Female & $51-60$ & Business/pleasure/holiday & Alone & Repeat \\
Simone & Female & $18-30$ & Pleasure/holiday & Friends & First time \\
Oscar & Male & $18-30$ & Pleasure/holiday & With partner & First time \\
Ruben & Male & $51-60$ & Pleasure/holiday & With partner & First time \\
Mila & Female & Over 61 & Pleasure/holiday & With partner & First time \\
Leonie & Female & $18-30$ & Studies/pleasure/holiday & With friends & First time \\
Sophie & Female & $18-30$ & Pleasure/holiday & With partner & First time \\
Joshua & Male & $31-40$ & Pleasure/holiday & With partner & First time \\
Hannah & Female & $18-30$ & Pleasure/holiday & With partner & First time \\
Clara & Female & $18-30$ & Studies/pleasure/holiday & With friends & First time \\
Felix & Male & $18-30$ & Pleasure/holiday & With partner & First time \\
Noah & Male & $31-40$ & Pleasure/holiday & With partner & First time \\
Lina & Female & $31-40$ & Pleasure/holiday & With partner & Repeat \\
Tess & Female & $18-30$ & Research/pleasure/holiday & Alone & First time \\
Isaac & Male & $41-50$ & Pleasure/holiday & With family & First time \\
\hline
\end{tabular}

Note: *All names are pseudonyms

Data analysis followed a thematic analysis approach (Braun \& Clarke, 2013), while data interpretation was done using the theoretical lens of the Appropriation Theory, with Caru and Cova's (2006) study as a reference point. At the start of the data analysis process, all audio-recorded interviews were transcribed by the author herself as transcribing was considered as part of the analysis (Kvale, 2007). Then, the transcripts were read and re-read to immerse in the data (Braun \& Clarke, 2013). With these readings, coding commenced where the researcher noted different actions taken by participants when interpreting ICH experiences. As presented in Table 2, the emerging themes mapped on to the three stages of appropriation - nesting, investigating, and stamping. 
Table 2: Theme Descriptions and Codes

\begin{tabular}{|c|c|c|}
\hline Theme & Description & Codes \\
\hline Nesting & $\begin{array}{l}\text { Ways in which tourists } \\
\text { identify familiar elements in } \\
\text { a new ICH experience }\end{array}$ & $\begin{array}{l}\text { - } \\
\text { expeflecting on immediate travel } \\
\text { - } \quad \text { Reflecting on past travel experiences } \\
\text { in culturally similar destinations } \\
\text { - } \quad \text { Relating to non-travel cultural } \\
\text { exposures }\end{array}$ \\
\hline Investigating & $\begin{array}{l}\text { Techniques used by tourists } \\
\text { to explore a new ICH } \\
\text { experience }\end{array}$ & 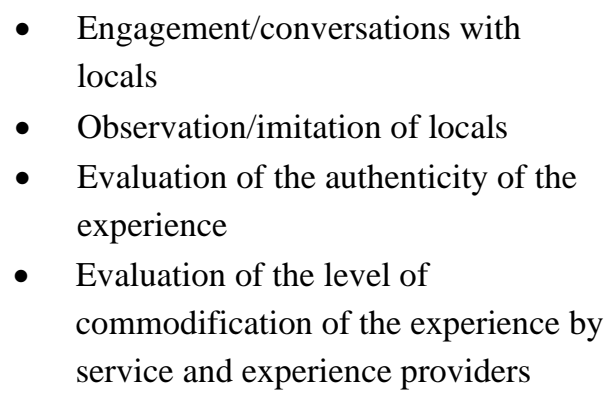 \\
\hline Stamping & $\begin{array}{l}\text { New meanings assigned to } \\
\text { ICH encounters }\end{array}$ & $\begin{array}{l}\text { - } \quad \text { Religion-related interpretations } \\
\text { - Locals' values-related interpretations } \\
\text { - Locals' lifestyle-related } \\
\text { interpretations }\end{array}$ \\
\hline
\end{tabular}

To establish trustworthiness, Guba's constructs (Shenton, 2004) which consists of credibility (i.e., presenting a true picture), transferability (i.e., providing sufficient details about the context), dependability (i.e., enabling repetition of the study), and confirmability (i.e., showing that the findings emerge from the data) were considered. Accordingly, credibility was addressed by establishing ecological validity by considering tourist encounters in Sri Lanka in their living immediacy (Braun \& Clarke, 2013). This credibility was further strengthened in the data collection stage by encouraging participants to provide honest opinions, and in the data interpretation stage by presenting clear think narratives and evidence from past literature (Shenton, 2004). Transferability was ensured by disclosing the specific context in which the study was conducted, sample characteristics of the participants, and the data analysis process (Braun \& Clarke, 2013; Shenton, 2004). Then, to meet the criteria of dependability, a clear description of the theoretical lens, data analysis, and theme descriptions have been given. Finally, for confirmability and to ensure that researcher bias is minimised, think narratives of the participants are accompanied by engaging descriptions closely informed by the selected theoretical lens. 


\section{Findings and Discussion}

\section{Nesting}

During the first stage of appropriation - nesting, individuals isolate familiar elements of an experience using points of anchorage thus becoming comfortable with it (Caru \& Cova, 2006). This isolation is the first step that helps consumers create a comfortable nest from which they can safely explore other new aspects of the experience (St James et al., 2018). Demonstrating this phenomenon, participants expressed that because of their past travel experiences, they "knew about", "felt familiar" and "recognised" certain elements of new ICH experiences they encountered in Sri Lanka. For example, Maja (female, above 61 years, Swedish) describes how previous conversations with locals (i.e., point of anchorage) helped her with the experience of going to a Buddhist temple (i.e., ICH category of social practices, rituals and festive events) creating a sense of familiarity of the expected behaviour.

When we went on tours before, we have been in a car ourselves but the driver, I mean we found that he was really good he would tell us when we were going to a temple what we should wear, how to behave. It was really good. So, when we went to the temples, we knew what to do and didn't feel lost.

Another similar instance of how a past travel experience supported the creation of a comfortable nest is demonstrated in Oscar's (male, 18-30 years, Danish) explanation below. He expresses that his food experiences in India (i.e., point of anchorage) helped him enjoy Sri Lankan cuisine (i.e., ICH category of gastronomy and culinary practices).

Yeah about the food, I probably compared it to like some of the other countries in Asia, specially India. It probably looks like the same as India, but I like the Sri Lankan food more actually than India.

Going beyond travel experiences, for Noah (male, 31-40 years, German), an experience of cooking with a known Sri Lankan family back at home (i.e., point of anchorage) created the familiarity needed to learn about new food preparation techniques (i.e., ICH category of gastronomy and culinary practices) during his trip in Sri Lanka.

Yeah, we had a chance to do a cooking lesson in our second hotel. The chef did a cooking lesson to show us how he makes a sambal and a chicken curry. It was very nice and that is what we did to learn. It was a mixed thing, we could assist the chef. You know we could assist him when making the chicken curry and also the sambal. Because we have cooked with that Sri Lankan family before we recognised some things it was easy for us to catch up and remember it. Yeah, we enjoyed that one. 
Thus, consistent with findings by St James et al. (2018) these excerpts demonstrate how past travel experiences like in the case of Maja and Oscar and past non-travel cultural exposures like in the case of Noah served as points of anchorage to create a 'nest' or a sense of familiarity with new ICH experiences helping them comprehend and enjoy those experiences more. This connection tourists build, and feel are important in the context of heritage experiences because it is considered as 'the essence' of such encounters (Chronis, 2005).

\section{Investigating}

During the second stage of appropriation - investigating, individuals explore elements of an experience that they find unfamiliar using different techniques. For example, St James et al. (2018) show that film tourists follow two approaches for this: investigating the plot and characters on-site (i.e., by exploring new areas and reenacting certain scenes) and revisiting the film (i.e., by watching the film again or showing intention of watching). Further, Caru and Cova (2006) identify observing events and discovering positive or negative aspects of experiences as investigating. Consistent with these, when experiencing ICH, tourists evidently exhibit six visitor behaviours that include attending religious rituals, ceremonies, festivals and events; gathering knowledge; socialising with locals; mirroring locals; observing locals and their practices and activities; and reliving the local culture (Alahakoon \& Udunuwara, 2018). More specifically, engagement and conversations with locals, and observation and imitation of locals' behaviour appeared as relevant to the stage of investigating. The following excerpt from the interview of Isaac (male, 41-50 years, British) exemplifies how he enjoyed the practice of eating with his hand (i.e., ICH category of gastronomy and culinary practices) for the first-time using visitor behaviours of observing locals and mirroring them (i.e., investigating).

When I was at a homestay in Sigiriya [a popular travel destination in Sri Lanka], I tried eating with my hands. My host said I did a good job [laughs]. That is because I could remember how the locals ate at the restaurant, I told you about. It was difficult but I was ok but my friend whom I got to know during the trip struggled. It's strange how the food actually tasted better like that [laughs].

Apart from such personal investigating techniques, Caru and Cova (2006) and St James et al. (2018) show that third parties such as a 'Maestro' in a concert and a tour operator in the context of film tourism play important roles in reducing distance with an experience by providing guidance and knowledge to visitors. A similar finding manifests from this study where locals such as the tour guides, drivers, staff and the public consciously or unconsciously, facilitated the stage of investigating by 
providing the required guidance and knowledge for tourists. Such engagement with locals is considered to have a positive influence on ICH experiences of tourists (Lopez-Guzman \& Gonzalez Santa-Cruz, 2016). This is demonstrated in Hannah's (female, 18-30 years, German) comment below showing how the presence of a local friend facilitated meaning attachment for a new ICH experience: a visit to a Hindu temple (i.e., ICH category of social practices, rituals and festive events).

Um I think it was the first trip to the Hindu temple with a friend of Janina [referring to a friend] because they were explaining everything. So, we ask her about everything about the gods: Why do you clap three times? Why you have to walk around this? It was really, really interesting.

Another key discussion regarding investigating is the role of service and experience providers. As St James et al. (2018) highlight, 'staged' references might lessen the authenticity of tourist experiences, where phrases like "it's not real anymore" were expressed by their participants while some even questioned the ethicality of it. Even though authenticity of tourist experiences takes different approaches (Wang, 1999) the definition of authenticity as given by Sharpley (1994 as cited in Wang, 1999, p. 350-351), where it stands for "traditional culture and origin, a sense of the genuine, and the real or the unique" is seen as most appropriate here. Besides, ICH is often synonymous with authenticity (Wesener, 2017) with ICH elements such as locals, their customs and presence of religious practitioners perceived as indicators of authenticity (Nguyen \& Cheung, 2016). Complementing the idea presented by St James et al. (2018), participants of this study also expressed that they prefer more authentic ICH experiences. For example, Tess's (female, 18-30 years, Dutch) comment on village experiences given below display both aspects of how experiences staged during a visit can be viewed as unrealistic and unethical. That is, she points out that even though a village experience (i.e., ICH category of knowledge and practices concerning nature and the universe) is important to get to know ways of life of locals, she has ethical concerns regarding this due to the invasion of privacy and disruption of the villagers' life.

On the one hand I agree that it's important to see because it's nice to see for a tourist a village and how people live in their day to day. But for me there is - are ethical issues. Because it shouldn't become an experience like a zoo because that's where they live. You know taking pictures. It's a very dangerous zone to be in. You don't know when it's real and it's fake. So, you have to take permission to take photos. So, there is an ethical issue.

Thus, it is evident that an individual's beliefs and values about authenticity pulls them back from further investigating certain experiences. This is an idea that surfaces 
in heritage literature where commodification of heritage assets was found to have a negative effect on perceptions of authenticity of those assets (Nguyen \& Cheung, 2016). Therefore, labelling experiences as 'fake' or 'unethical' could hinder the tourist experience as they often result in rejection of the experience or disappointment. Echoing this idea, some participants expressed a dislike to experiences they identified as 'fake'. For example, Clara (female, 18-30 years, Dutch) feels like the way service and experience providers try to portray certain experiences as authentic is just a 'marketing trick' raising a red flag to staged performances and events.

I've been seeing quite some places where they say you can have authentic food... it doesn't seem natural in some way. Of course, you can see some authentic things here but, sometimes I feel like it's a marketing trick for people to jump into that.

Apart from staged experiences, some environmental factors can act as barriers for investigating an experience (St James et al., 2018). The excessive commodification of tourist experiences can be identified as one such barrier, particularly in the context of heritage sites (Chronis, 2005). This was found to be true regarding ICH experiences as well. As such, 'touristy' sites and experiences characterised by over pricing and overcrowding negatively affect the stage of investigating creating a further disconnect from new experiences. This can also result in negative tourist behaviours and intentions such as negative word of mouth as in the case of Leonie (female, 18-30 years, German).

So, if I would advise someone to always like if you have the chance then always go off the main tourist path and try to experience stuff like that because most of the time they are more authentic... if you have the chance always like take the chance and go to a family eat rice and curry or go on the Perahara [a parade] with friends or see a dancing in a concert in small setting where no other foreigners are...

Overall, when tourists are in the stage of investigating, the influence of third parties evidently facilitates the process of investigating while concerns regarding authenticity and excessive commercialisation impede the process.

\section{Stamping}

In the third and final stage of appropriation - stamping, consumers engage in meaning making related to the experience. Such meaning is built through the development of impressions of a situation and the meaning attributed to those situations (Caru \& Cova, 2006). This aligns with the idea that it is not tourist destinations that are important in creating tourist experiences, but the individual tourist him/herself (Larsen, 2007). Caru and Cova (2006) identify such meaning 
attachment through statements like 'it seems to me', 'in my opinion' and other common meanings referring to feelings of well-being, growth and gratification. They further add that the consumer's own history, relationships with family members or friends, and past aesthetic experiences affect the meaning they give to an experience. Similar evidence from this study demonstrates this in the context of ICH.

Accordingly, it is evident that meanings attributed to ICH experiences commonly revolve around the importance given to religion in local activities, the hardworking nature of locals, their values, and relaxed lifestyle. One such example is visible in Mila's (female, above 61 years, Dutch) observation of a difference in the gender representation of men vs. women at work in Sri Lanka compared to other Asian countries she has travelled to. She then attributes the presence of religious diversity as a reason why it could be so. Such imaginative interpretations are a known facilitator of tourists' connection to heritage experiences at travel destinations (Chronis, 2005).

... if you think about something specially Sri Lankan, you see a lot of men working and in other Asian countries you see a lot more women working and could be because there are Hindu people here, Buddhist people here and Christians and Muslims...

Thus, it is apparent that past travel experiences help tourists prepare and make sense of new experiences related to ICH specially in the absence of formal sources of information. However, it should be cautioned that such past travel experiences affect the sense of novelty and uniqueness of new experiences. For example, Leonie (female, 18-30 years, German) describes how two people (i.e., herself who was not familiar with the culture of Sri Lanka and a friend who had previous experience with a similar culture) reacted to the same experience differently.

... a friend of mine she has been to India before so she already knew how the similarities to the Sri Lankan culture and how it's going to be and how she experienced some stuff while I'm so overwhelmed but other stuff because she had seen it once before and I see it for the first time of my life and I'm just so overwhelmed and impressed and talk about it for ages...

These evidences illustrate how tourists go through the stages of nesting, investigating and stamping to construct the meaning of new $\mathrm{ICH}$ experiences using their accumulated past travel and at times non-travel cultural exposures.

\section{The Chain of Reflective Experiences}

Apart from illustrating how tourists attach meaning to ICH experiences, findings show that discrete experiences created in different places and times are connected 
because of tourists' recollection and reflection of past travel experiences. This is because of the synergistic effects created when tourists carry forward memories of one experience to construct meaning of another experience. This idea is apparent in Ben's description on how witnessing a ceremonial gathering of locals in Thailand helped him give meaning to a new ICH experience in Sri Lanka. Specifically, the recollection of a past travel experience helped Ben create a sense of familiarity with the new encounter (i.e., nesting), prompting him to observe the event more closely (i.e., investigating), resulting in an interpretation related to locals' attitude towards and treatment of religious clergy (i.e., stamping). A further example is illustrated in Felix's explanation of his food experience where he drew parallels between consumption practices in Sri Lanka and Spanish cuisine (i.e., nesting) to deduce expected behaviour (i.e., stamping).

The only thing I'd say is the Buddhist monks and how everybody reveres them so much here. I was out Sunday night in town they must have been quite important monks, because they had a lot of followers. I don't know who they were I was just passing them. They were all lined up in a street which is nice to see that those are respected by all the local people. I was in Thailand last year when the king died. It was the same thing there. There was a big outpouring by the local people. I think the same thing happens here (Ben, male, above 61 years, British)

For me it reminded me of tapas. You know what tapas is like. There were many several dishes across the table... and you want to try them all so you avoid eating too much of one thing to make sure you taste all of the foods (Felix, male, 18-30 years, Danish)

Other than past travel experiences, non-travel cultural exposures also provide nests on which further investigation of new ICH experiences are done. For example, Felix further draws from experiences related to his own religious practices to give meaning to rituals he witnessed at a Buddhist temple. Accordingly, the recollection and reflection of church practices at home (i.e., nesting), prompted him to critically observe Buddhist rituals (i.e., investigating), which he then attributed to the 'serious' religious values locals hold (i.e., stamping).

...people gathered and they have these rows and everyone was just skipping past you instead of like having like a normal queue to go watch the tooth [referring to a sacred relic worshipped by Buddhists]. So, we skipped the line and went straight for the prayers... But you seemed pretty serious about your religion. Everything just stops for minute and you start praying. It is different from Denmark because there is no time for praying except for a marriage or for Christmas.

This phenomenon of interconnected travel experiences also highlights the scattered nature of tourist experiences across different spaces as opposed to residing 
at a single point where the experience is staged or encountered. Encapsulating this idea that discrete travel experiences which are geographically and temporally separated influence each other, 'the chain of reflective experiences' is proposed with theoretical underpinning in the Appropriation Theory. This notion that experiences are interrelated (Florida, 2002) and have synergistic effects (Laing et al., 2014) exists in literature but is not explored as a holistic concept using evidence. Thus, the chain of reflective experiences proposes that through a process of nesting, investigating and stamping tourists use geographically and temporally separated travel experiences to make sense of new travel experiences as demonstrated using the specific travel context of ICH.

Using the Appropriation Theory, the chain of reflective experiences illustrates that tourists' recollection of and reflection on past travel experiences create a sense of familiarity by becoming anchorage points (i.e. nesting), helping them get comfortable with new elements of a travel experience, which they will investigate further using techniques such as attending religious rituals, ceremonies, festivals and events; gathering knowledge; socialising with locals; mirroring locals; and observing locals and their practices (i.e. investigating), resulting in subjective meaning assignment (i.e., stamping) specially in the context of ICH. As this cycle of recollection and reflection seems to be continuous, stamping done on one experience can become a nest in another, giving rise to the idea of a 'cycle'. Caru and Cova (2006) also acknowledges the occurrence of mini cycles of nesting during the experience of watching a classical music concert. As they point out, this is mainly because nesting provides a starting point to some experiences and a finishing point to others. Thus, this phenomenon shows how experiences consumed in different spaces and times affect each other creating synergistic effects resulting in a 'chain of reflective experiences' that enriches tourist experiences.

The main implication of the chain of reflective experiences is that experiences that serve as nests for tourists help them prepare for other experiences reducing the uncertainty associated with such experiences. Rogoff (1995) describes a concept identified as participatory appropriation, which is similar to this idea. Participatory appropriation is where, "the personal process by which, through engagement in an activity, individuals change and handle a later situation in ways prepared by their own participation in the previous situation" (Rogoff,1995, p. 3). Holt (1995) suggests that to a large extent, consumers conjure up competencies to become the main builders and co-creators of the consumption experience. Further, in this process, the autonomy tourists have during an experience contributes to the degree of immersion (Lunardo 
\& Ponsignon, 2020). Aligning with these propositions, this paper suggests that such preparedness as identified by Rogoff (1995) and competencies as identified by Holt (1995) are built through past travel experiences of tourists. This is exemplified in Noah's (male, 31- 40 years, German) description of a visit to a temple in Sri Lanka. This description indicates that past experiences and knowledge prepares tourists to make sense of and behave in a way that they perceive as appropriate during new cultural encounters.

Then we visited some temples but we didn't see any special events in these temples. I think we knew this before and we were prepared for it you know [laughs]. That we have to take our shoes off, the girls had to wear something over the knees and over the shoulders. So we knew about it and we had to do this...We tried to not to stand in front of the Buddha and not to show our back to Buddha you know what I mean... We wanted to give respect to the people who are living there and meditating.

\section{Theoretical and Practical Implications}

The theoretical implications of this paper are two-fold. Firstly, in response to calls for research to study memory dimensions such as recollections (Manthiou et al., 2014), past experiences (Loureiro, 2014) and the effect past experiences have on new experiences (Hwang \& Seo, 2016) within experience literature, and meaning generation (Freeman, 2010) and memory creation (Kim, 2010) of ICH in heritage literature, this study establishes that tourists go through a process of nesting, investigating and stamping to construct meaning of ICH experiences, especially in the absence of formal sources of information. With that, this study puts forward the Appropriation Theory as a useful tool to explain how tourists construct meaning of travel experiences. Secondly, this paper initiates a discussion on the chain of reflective experiences which is a holistic concept that encapsulates the idea that experiences that are separated geographically and temporally are interrelated with synergistic effects. This is different to how experiences are currently viewed by some scholars such as Pine and Gilmore (1999) who focused on experiences generated at a particular point of time in a specific place. In summary, using the context of ICH experiences, this paper suggests that the process of recollection and reflection of past travel experiences, create rich travel experiences even though the resulting meaning attachments are subjective and different to what might be envisioned by destination marketers and the host community.

For practitioners, this research has few implications. One is that even though subjective interpretations of travel experiences by tourists are inevitable, Destination Management Organisations (DMOs) should take necessary steps to reduce 
misinterpretations of ICH experiences. Provision of sufficient information to tourists through information boards and educating them about the destination's people and livelihoods prior to visitation are some possible solutions. However, in doing so, it is important to consider the dilemma of whether such a planned approach of presenting ICH might reduce the authenticity of the encounter which evidently act as a barrier for tourists to connect with it. Overall, this paper provides useful insights to practitioners on the overlooked phenomenon of how tourists attach meaning to new and unfamiliar experiences which will help them better plan and market their offers.

\section{Limitations and Further Research}

This research was limited to European tourists to whom ICH experiences in a destination like Sri Lanka is quite novel and out-of-the-ordinary. Thus, their process of giving meaning to such experiences might largely differ from tourists representing other geographic regions such as tourists with South Asian backgrounds, whose cultures have greater similarities to the Sri Lankan culture, and therefore, could have closer parallels to their everyday life. This opens new research possibilities of replicating the study for other tourist demographics. Further a practical constraint of the chain of reflective experiences is that, as an independent organisation, a DMO or a tourism service or experience provider will not be able to control or even manage the interrelatedness and synergistic effects of these temporally and spatially diverse experiences. However, at higher levels of tourism planning, when defining the overall tourist experience, this can be considered. In doing so DMOs should be mindful not to adapt ICH to suit needs and expectations of tourists as they are currently understood; because that could result in a loss of authenticity (Lenzerini, 2011). In addition to the above, it should be noted that this paper only provides preliminary evidence for the chain of reflective experiences and further research is needed to establish this concept more concretely.

\section{Conclusion}

This paper set out to understand how tourists give meaning to ICH experiences through the recollection and reflection of their own past travel experiences. In line with this, findings illustrate that when tourists encounter new ICH experiences, past travel experiences create a sense of familiarity with new experiences supporting further investigation of those experiences, finally resulting in subjective meaning assignments. Such meaning assignment was evident to be very personal and unique and at times different to the meaning attributed by destination marketers and the host community. This indicates that tourists often create their own interpretations of the 
ICH of a destination. Deriving from these findings, this paper proposes 'the chain of reflective experiences', a holistic concept of viewing how tourists construct meaning of travel experiences.

\section{Declaration of Conflicting Interests}

The authors declared no potential conflicts of interest with respect to the research, authorship, and publication of this article.

\section{Acknowledgements}

Comments given by Dr UKMI Udunuwara, Professor JASK Jayakody, Dr AKL Jayawardana, and Professor Twan Huybers to improve this paper are acknowledged with much appreciation.

\section{References}

Ahmad, Y. (2006). The scope and definitions of heritage: From tangible to intangible. International Journal of Heritage Studies, 12(3), 292-300. https://doi.org/10.1080/13527250600604639

Aho, S. (2001). Towards a general theory of touristic experiences: Modelling experience process in tourism. Tourism Review, 56(3/4), 33-37. https://doi.org/10.1108/eb058368

Alahakoon, T. H., \& Udunuwara U. K. M. I (2018). Visitor experiences generated through intangible cultural heritage: With special reference to Sri Lanka as a tourist destination. Sri Lankan Journal of Management, 23(1), 1-40.

Ali, F. (2015). Heritage tourist experience, nostalgia, and behavioural intentions. Anatolia, 26(3), 472-475. https://doi.org/10.1080/13032917.2015.1013477

Aubert-Gamet, V. (1997). Twisting servicescapes: Diversion of the physical environment in a re-appropriation process. International Journal of Service Industry Management, 8(1), 26-41. https://doi.org/10.1108/09564239710161060

Beardslee, T. (2016). Whom does heritage empower, and whom does it silence? Intangible cultural heritage at the Jemaa el Fnaa, Marrakech. International Journal of Heritage Studies: Themed Section: Critical Ethnographies of Urban Heritage in the Western Mediterranean Region, 22(2), 89-101. https://doi.org/10.1080/13527258.2015.1037333

Bendix, R. (2002). Capitalizing on memories past, present, and future: Observations on the intertwining of tourism and narration. Anthropological Theory, 2(4), 469-487. https://doi.org/10.1177/14634990260620567 
Björk, P., \& Kauppinen-Räisänen, H. (2016). Local food: A source for destination attraction. International Journal of Contemporary Hospitality Management, 28(1), 177-194. https://doi.org/10.1108/IJCHM-05-2014-0214

Blundell, D. (2013). Vedda (Vanniyaletto) as folk life: Intangible cultural heritage in Sri Lanka. Electronic Cultural Atlas Initiative (ECAI), 32(1), 23-28. http://dx.doi.org/10.7152/bippa.v26i0.12006

Braun, V., \& Clarke, V. (2013). Successful qualitative research: a practical guide for beginners. SAGE.

Braun-LaTour, K. A., Grinley, M. J., \& Loftus, E. F. (2006). Tourist memory distortion. Journal of Travel Research, 44(4), 360-367. https://doi.org/10.1177/0047287506286721 .

Caru, A., \& Cova, B. (2003). Revisiting consumption experience: A more humble but complete view of the concept. Marketing Theory, 3(2), 267-286. https://doi.org/10.1177/14705931030032004

Caru, A., \& Cova, B. (2006). How to facilitate immersion in a consumption experience: Appropriation operations and service elements. Journal of Consumer Behaviour, 5(1), 4-14. https://doi.org/10.1002/cb.30

Cetin, G., \& Bilgihan, A. (2016). Components of cultural tourists' experiences in destinations. Current Issues in Tourism, 19(2), 137-154. https://doi.org/10.1080/13683500.2014.994595

Chandralal, L., \& Valenzuela, F. (2015). Memorable tourism experiences: Scale development. Contemporary Management Research, 11(3), 291-310. https://doi.org/10.7903/cmr.13822

Chen, C.-F., \& Chen, F.-S. (2010). Experience quality, perceived value, satisfaction and behavioral intentions for heritage tourists. Tourism Management (1982), 31(1), 29-35. https://doi.org/10.1016/j.tourman.2009.02.008

Chronis, A. (2005). Our Byzantine heritage: Consumption of the past and its experiential benefits. Journal of Consumer Marketing, 22(4), 213-222. https://doi.org/10.1108/07363760510605326

Firat, A. F., Dholakia, N., \& Venkatesh, A. (1995). Marketing in a postmodern world. European Journal of Marketing, 29(1), 40-56. https://doi.org/10.1108/03090569510075334

Firat, A. F. (2001). The meanings and messages of Las Vegas: The present of our future. Management, 4(3), 101-120. https://www.cairn.info/revue-management2001-3-page-101.htm

Florida, R (2002). The rise of the creative class. Basic Books

Freeman, C. G. (2010). Photosharing on Flickr: Intangible heritage and emergent publics. International Journal of Heritage Studies, 16(4-5), 352-368. https://doi.org/10.1080/13527251003775695 
Hansen, A. H., \& Mossberg, L. (2017). Tour guides' performance and tourists' immersion: facilitating consumer immersion by performing a guide plus role. Scandinavian Journal of Hospitality and Tourism, 17(3), 259-278. https://doi.org/10.1080/15022250.2016.1162347

Holt, D. B. (1995). How consumers consume: A typology of consumption practices. Journal of Consumer Research, 22(1), 1-16. https://doi.org/10.1086/209431

Hwang, J., \& Seo, S. (2016). A critical review of research on customer experience management. International Journal of Contemporary Hospitality Management, 28(10), 2218-2246. https://doi.org/10.1108/IJCHM-04-20150192

Kim, J.-H. (2010). Determining the factors affecting the memorable nature of travel experiences. Journal of Travel and Tourism, 27(8), 780-796. https://doi.org/10.1080/10548408.2010.526897

Kim, J., Ritchie, J. R. B., \& Tung, V. W. S. (2010). The effect of memorable experience on behavioral intentions in tourism: A structural equation modeling approach. Tourism Analysis, 15(6), 637-648. https://doi.org/10.3727/108354210X12904412049776

Kvale, S. (2007). Doing interviews. SAGE.

Laing, J., Wheeler, F., Reeves, K., \& Frost, W. (2014). Assessing the experiential value of heritage assets: A case study of a Chinese heritage precinct, Bendigo, Australia. Tourism Management, 40(1), 180-192. https://doi.org/10.1016/j.tourman.2013.06.004

Larsen, S. (2007). Aspects of a psychology of the tourist experience. Scandinavian Journal of Hospitality and Tourism, 7(1), 7-18. https://doi.org/10.1080/15022250701226014

Lenzerini, F. (2011). Intangible cultural heritage: The living culture of peoples. The European Journal of International Law, 22(1), 101-120. https://doi.org/10.1093/ejil/chr006

Li, Y. (2000). Geographical consciousness and tourism experience. Annals of Tourism Research, 27(4), 863-883. https://doi.org/10.1016/S01607383(99)00112-7

Liyanag, U., \& Jayawardena, C. (2013). Towards a positioning strategy for tourism in post-war Sri Lanka. Worldwide Hospitality and Tourism Themes, 5(5), 477485. https://doi.org/10.1108/WHATT-05-2013-0029

Lopez-Guzman, T., \& Gonzalez Santa-Cruz, F. (2016). International tourism and the UNESCO category of intangible cultural heritage. International Journal of Culture, Tourism and Hospitality Research, 10(3), 310-322. https://doi.org/10.1108/IJCTHR-03-2015-0025 
Loureiro, S. M. C. (2014). The role of the rural tourism experience economy in place attachment and behavioral intentions. International Journal of Hospitality Management, 40(1), 1-9. https://doi.org/10.1016/j.ijhm.2014.02.010

Lunardo, R., \& Ponsignon, F. (2020). Achieving Immersion in the tourism experience: The role of Autonomy, Temporal Dissociation, and Reactance. Journal of Travel Research, 59(7), 1151-1167. https://doi.org/10.1177/0047287519878509

Manthiou, A., Lee, S., Tang, L., \& Chiang, L. (2014). The experience economy approach to festival marketing: Vivid memory and attendee loyalty. Journal of Services Marketing, 28(1), 22-35. https://doi.org/10.1108/JSM-06-2012-0105

Misfud, M., Cases, A., \& N'Goala, G. (2015). Service appropriation: How do customers make the service their own? Journal of Service Management. 26(5). 706-725. https://doi.org/10.1108/JOSM-04-2015-0136

Mitsche, N., Vogt, F., Knox, D., Cooper, I., Lombardi, P., \& Ciaffi, D. (2013). Intangibles: enhancing access to cities' cultural heritage through interpretation. International Journal of Culture, Tourism and Hospitality Research, 7(1), 68-77. https://doi.org/10.1108/17506181311301381

Nguyen, T., \& Cheung, C. (2016). Toward an understanding of tourists' authentic heritage experiences: Evidence from Hong Kong. Journal of Travel \& Tourism Marketing, 33(7), 999-1010. https://doi.org/10.1080/10548408.2015.1075460

Nuryanti, W. (1996). Heritage and postmodern tourism. Annals of Tourism Research, 23(2), 249-260. https://doi.org/10.1016/0160-7383(95)00062-3

O'Hare, G., \& Barrett, H. (1993). The fall and rise of the Sri Lankan tourist industry. Geographical Association, 78(4), 438-442. Retrieved from https://www.jstor.org/stable/40572558

Park, S., \& Santos, C. A. (2017). Exploring the tourist experience: A sequential approach. Journal of Travel Research. 56(1), 16-27. https://doi.org/10.1177/0047287515624017

Petronela, T. (2016). The importance of the intangible cultural heritage in the economy. Procedia Economics and Finance, 39, 731-736. https://doi.org/10.1016/S2212-5671(16)30271-4

Pine, B. J., \& Gilmore, J. H. (1999). The experience economy: Work is theater and every business a stage. Harvard Business Press.

Poria, Y., Butler, R., \& Airey, D. (2003). The core of heritage tourism. Annals of Tourism Research, 30(1), 238-254. https://doi.org/10.1016/S01607383(02)00064-6

Ritchie, J. R. B., \& Hudson, S. (2009). Understanding and meeting the challenges of consumer/tourist experience research. International Journal of Tourism Research, 11, 111-126. https://doi.org/10.1002/jtr.721 
Rogoff, B. (1995). Observing sociocultural activity on three planes: Participatory appropriation, guided participation, and apprenticeship. In J. V. Wertsch, P. del Rio, \& A Alvarez (Eds.), Sociocultural studies of mind (pp. 139-164). https://doi.org/10.1017/CBO9781139174299.008

Shenton, A. (2004). Strategies for ensuring trustworthiness in qualitative research projects. Education for Information, 22(2), 63-75. https://content.iospress.com/articles/education-for-information/efi00778

St-James, Y., Darveau J., \& Fortin, J. (2018). Immersion in film tourist experiences. Journal of Travel and Tourism Marketing, 35(3), 273-284. https://doi.org/10.1080/10548408.2017.1326362

Swensen, G., Jerpåsen, G., Sæter, O., \& Tveit, M. (2013). Capturing the intangible and tangible aspects of heritage: Personal versus official perspectives in cultural heritage management. Landscape Research, 38(2), 203-221. https://doi.org/10.1080/01426397.2011.642346

Timothy, D., \& Boyd, S. (2006). Heritage tourism in the 21st Century: Valued traditions and new perspectives. Journal of Heritage Tourism, 1(1), 1-16. https://doi.org/10.1080/17438730608668462

Toffler, A. (1980). The third wave. William Morrow.

Tung, V. W. S., \& Ritchie J. R. B. (2011). Exploring the essence of memorable tourism experiences. Annals of Tourism Research. 38(4), 1367-1386. https://doi.org/10.1016/j.annals.2011.03.009

United Nations Educational, Scientific and Cultural Organisation. (1972). Convention concerning the protection of the world cultural and natural heritage. https://whc.unesco.org/archive/convention-en.pdf

United Nations Educational, Scientific and Cultural Organisation. (2003). Convention for the safeguarding of the intangible cultural heritage. https://ich.unesco.org/en/convention

Volo, S. (2009). Conceptualizing experience: A tourist based approach. Journal of Hospitality Marketing \& Management: The Marketing of Hospitality and Leisure Experiences, 18(2-3), 111-126. https://doi.org/10.1080/19368620802590134

Wang, N. (1999). Rethinking authenticity in tourism experience. Annals of Tourism Research. 26(2), 349-370. https://doi.org/10.1016/S0160-7383(98)00103-0

Wesener, A. (2017). Adopting "things of the little": Intangible cultural heritage and experiential authenticity of place in the Jewellery Quarter, Birmingham. International Journal of Heritage Studies, 23(2), 141-155. https://doi.org/10.1080/13527258.2016.1246465 


\section{Alahakoon}

Wijetunga, C., \& Sung, J. (2015). Valuing the cultural landscapes past and present: Tea plantations in Sri Lanka. Landscape Research: Cultural Landscapes in the 21st Century: Issues and Opportunities, 40(6), 668-683. https://doi.org/10.1080/01426397.2015.1057803

Wimalaratana, W. (2016). Cultural tourism potential in the north central province of Sri Lanka. Social Affairs (Peradeniya), 1(4), 46-64. https://doaj.org/article/92e7ac5d9d424771a6821daab8aebed5

World Tourism Organization (2012), Tourism and Intangible Cultural Heritage.

Yelmi, P. (2016). Protecting contemporary cultural soundscapes as intangible cultural heritage: Sounds of Istanbul. International Journal of Heritage Studies, 22(4), 302-311. https://doi.org/10.1080/13527258.2016.1138237 